International Journal of English Language Studies (IJELS)

ISSN: 2707-7578

DOI: 10.32996/ijels

Website: https://al-kindipublisher.com/index.php/ijels

\title{
EFL Teachers' Code-switching in Post Lesson Discussion: A Window into English Supervision
}

AIGHALIYA ALKINDI ${ }^{1 *}$ and ISMAIL SHEIKH AHMAD ${ }^{2}$

${ }^{1}$ Research Scholar: Ph.D. Student, Department of Languages \& Literacy, Kulliyah of Education, International Islamic

University, Malaysia

${ }^{2}$ Professor in Language Education, Department of Languages \& Literacy, Kulliyah of Education, International Islamic

University, Malaysia

Corresponding Author: AIGHALIYA ALKINDI, E-mail: ummalmutaz.888@moe.om

ARTICLE INFORMATION

Received: September 02, 2020

Accepted: October 12, 2020

Volume: 2

Issue: 4

DOI: 10.32996/ijels.2020.2.4.6

\section{KEYWORDS}

Code-switching, Continuous

Professional Development, EFL

Teachers, Post Lesson Discussion,

English Supervision

\section{ABSTRACT}

Naturally, code-switching occurs in a normal conversation between bilingual speakers who are familiar with the spoken languages as an intellectual translanguaging process. A puzzling process, still in a positive way, that has been under the attention of linguists for decades regardless of the ethnographic or geographic characteristics of the spoken languages and/or their speakers. This research study explored this phenomenon from a pedagogical aspect that is directly linked with the Omani teachers of English Language of Cycle One ( $\left.{ }^{1} \mathrm{C} 1\right)$ Muscat Basic Education Schools (BES) as native speakers of Arabic. For the first time, yet beyond the classroom borders, the issue of code-switching is locally tackled from the continuous professional development outlook; the post lesson discussion ( ${ }^{2} \mathrm{PLD}$ ) or as also known, the post classroom observation discussion. Qualitatively, the researchers investigated this controversial phenomenon, in the world of foreign languages, from the perspective of the English Language Supervision; Supervisors and Senior Supervisors, in specific, in relation to its functions and the driving reasons, potential pros and cons and how it could be handled properly. The findings of this case study address future educational implications to the best practices of the PLD interaction language as well as to promote heightened understanding of the C1 EFL teachers' code-switching nature to manage it for the greater good of their continuous professional development (CPD).

\section{Introduction}

It is not extraordinary to observe bilinguals mix or switch between their native language and another foreign language while conversing with each other. In fact, it is regarded as an inevitable bilingual strategy that is not restricted only to English and Arabic languages (Omar \& llyas, 2018). This code-switching or, as also known as code-mixing, takes place in different contexts with varied amounts and degrees of emphasis. The switching between two languages, very often, does not come in equal portions where, very often, the target spoken language overweighs the other. Commonly, the target language for communication is mixed with the other language. Form an educational perspective, Omani English Language teachers, as native speakers of Arabic, are of no exception. They use Arabic in a number of contexts, in/outside the classroom for different reasons and with different audience; students, colleagues, Senior English Teacher (SET) or even the English Regional Supervisor (RS). From a global perspective, this issue has been investigated (e.g. Sert, 2005; Cantone 2007; Losey 2009) either as a bilingual linguistic phenomenon, in its own right, or as a pedagogical practice inside the classroom in the teacher's

${ }^{1}$ Cycle One : a government basic education school level that includes primary grades 1-4.

2 PLD : one-to-one conference takes place between the teacher and the supervisor after the classroom observation to discuss the observed remarks and future action plan.

K C AL-KINDI CENTER

$R$ D FOR RESEARCH AND Your gateway to word-class Your gateway to world-class research
Published by Al-KindiCenter for Research and Development. Copyright (c) the author(s). This is an open access article under CC BY license (https://creativecommons.org/licenses/by/4.0/) 
and the students' discourse. However, and from a local perspective, this issue has not been addressed neither by the linguists nor the pedagogics in Oman. In this sense, the researchers are keen to investigate qualitatively this linguistic phenomenon as used by many of the English language teachers teaching in the government BES C1 from the perspective of the Supervisors and Senior Supervisors as the top personnel of the English Supervision within the Ministry of Education (MoE) level and the immediate school field technical Supervisors for English teachers. Especially knowing that there is scarcity in researching code-switching within the Omani context in general and in the educational context in specific. Accordingly, this marks this case study as the first research of its kind to investigate and analyse the EFL teachers' codeswitching in $\mathrm{C} 1$ schools during the PLD from the English Supervision view point.

\section{Literature Review}

To Wardhaugh and Fuller (2014), 'code' as a terminology refers to a strategy which bilingual speakers use for communication purposes within the same discourse (Numan \& Carter, 2001, p. 275). From his side, Ansar (2017, p.31) identifies 'codemixing':

'Other phenomenon closely related to code-switching which takes place without a change of topic and can involve various levels of language such as phonology, morphology, grammatical structures or lexical items'.

As with regard to 'code-switching', Ansar (2017) perceives it as a skill which a bilingual speaker refers to by using more than one language in a conversation. In other words, Green \& Li, $(2014,2016: 1)$ elaborate:

'Bilingual speakers may insert single lexical forms from one language into the morph-syntactic frame of another or alternate between languages at clause boundaries. They may also engage in dense code switching with rapid changes of language within a clause during a conversational turn'.

In this sense, code-witching and code-mixing are two sides of the same coin which very often are used interchangeably as a sociolinguistic cognitive conversing skill. This meshing or alternation of mother tongue use (Arabic) with the other foreign language (English), as in this case study, is similarly known as bilingualism (Al Ma'ani \& Al Kindi, 2017). Nevertheless, the researchers are to use 'code-switching' as it literally manifests the phenomenon of switching between English-Arabic and Arabic-English throughout this research paper.

As non-native speakers of English and yet native speakers of Arabic, Omani teachers of English as a foreign language, as any other bilingual speaker, use code-switching in/outside the classroom to achieve interactional purposes. Being fully aware of the usefulness of code-switching in conversations, teachers refer to it to achieve communication as well as mutual understanding.

Regardless of the controversial nature of the EFL teachers' use of code-switching, particularly for the advocates of the communicative approach within the English learning environment (Sert, 2005), it is still of a central research attention for the potential functions which signals 'pedagogical and sociocultural functions of teachers' code-switching as part of their bilingual repertoire of professional practice', (Cahyani, Courcy \& Barnett, 2018, p.3). Sert (2005, p.2) explains that codeswitching is also used by the teachers, either on a conscious or subconscious level, to 'build intimate interpersonal relationships among members of a bilingual community'. This highlights the actual professional and humane rapport between the teachers and their RS and the SET. Moreover, Sert (2005) adds that teachers feel secure when using codeswitching; moving from the known (Native Language) to the unknown (Foreign Language). Wei (2005) remarks further that the teachers' 'rational choice' for code- switching is triggered by certain 'rights and obligations' as perceived in a given situational context.

According to Mattson and Burenhult (1999, p.61), EFL teachers use code-switching for 1) topic switch (e.g. altering language to the topic of discussion), 2) affective functions (e.g. expressing feelings and emotions), and 3) repetitive functions (e.g. using repetitively code switching to stress comprehension and clarity). However, there are other than the communicative conversational functions which influence EFL teachers to use code-switching away from the classroom context; in a one-toone professional framework as in the PLD, for example. this research intends to explore the so-called 'functional reasons' from an empirical perspective; as based on the accumulative supervisory school visits of the English RSs and/or Senior English RSs.

Form a local perspective, though being beyond the scope of this research study, the code-switching to Arabic by Omani EFL teacher has been researched, yet from the pedagogic classroom teaching and learning perspective (e.g. Al-Alawi, 2008; AlHadhrami, 2008; Al-Jadidi, 2009; Al-Shidhani, 2009; AlMa'ani \& AlKindi, 2017; AlKindi, Sheikh Ahmad, Al-Sharafi, Idrus, 2020). In addition, there is a handful of local researchers such as Ali (2020), Al-Qaysi (2016) and Tekin \& Al-Salmi (2019) who researched code-switching used by bilingual higher education students and their instructors from the socio-pragmatic and 
academic point of view. However, there are no whatsoever local researches carried out from the perspective of EFL teachers' CPD represented in the PLD.

In this respect, the researchers took the responsibility to contribute to this area of high research interest by highlighting the issue of the teacher's code-switching during the PLD as a linguistic phenomenon taking place outside the classroom context. The insightful findings and implications are hoped to better serve the professional growth of the English teachers on all linguistic and pedagogical level; the PLD communication language in particular.

\section{Methodology}

\subsection{Statement of Problem (SOP)}

Based on the field observations, as part of the English education and supervision, the researchers have noticed that the phenomenon of code-switching is commonly used by C1 EFL teachers, regardless of the motives, more than the EFL teachers of other school levels, C2 Basic Education (G5-10) and C3 Post Basic Education (G11-12). Having the phenomenon of native language use (Arabic) in the classroom investigated, the researchers are keen to closely study the use of Arabic in the form of code-switching as part of the post lesson discussion. Generally, this small scale qualitative study aims to investigate the phenomenon of code-switching by C1 EFL teachers during the PLD from the perspective of the English Supervision. This is through identifying to what extent code-switching can be 'a blockage or a deficiency' or may be considered as 'a useful strategy' (Sert, 2005) in the EFL teacher's short/long-term CPD.

\subsection{Research Questions}

Based on the above mentioned SOP, two major questions were generated to explore code-switching as perceived from the actual practices of C1 EFL teachers:

a) What is the English Supervision's perspective about code-switching?

b) Why C1 EFL teachers use code-switching in the PLD?

\subsection{Setting \& Selection of Informants}

This research explored code-switching used by C1 EFL teachers during the PLD from the perspective of an elite representative sample of English Language RSs and Senior RSs with significant experience ranges between 21-35 years of EFL education and supervision as part of Muscat Educational Governorate and the Supervision Section at MoE. The informants have worked closely and for a long time with a wide range of $\mathrm{C} 1$ teachers with different personalities and educational backgrounds throughout their supervisory field work. Hence, their responses are based on their best knowledge of C1 EFL teachers throughout the school and class visits, predominantly during the PLD.

The researchers put into consideration the gender factor in including the perceptions of both male and female RSs and Senior RSs, 8 in total, to stand on any potential significant findings related to the area of research, if any. The following table displays the details of the involved informants' gender, job title and work experience in years:

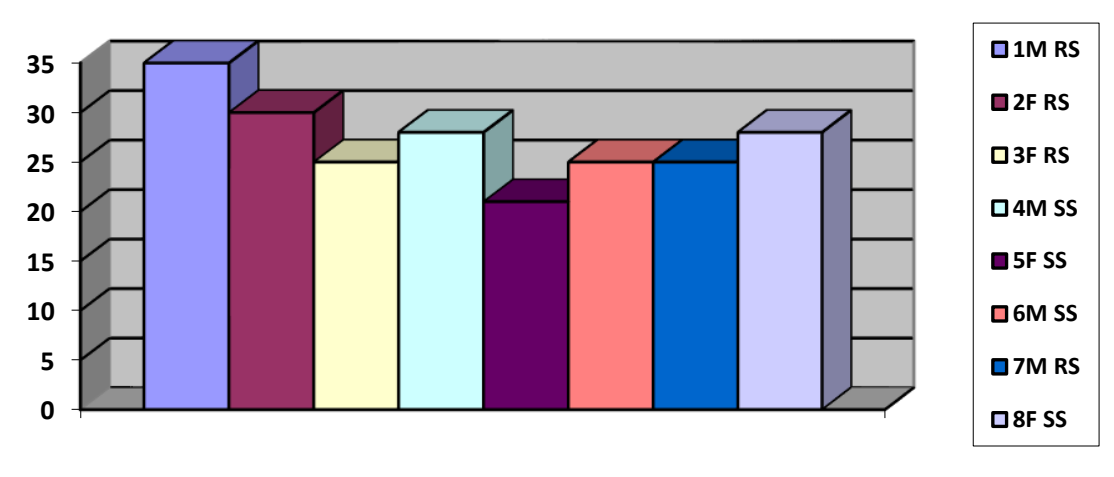

Figure 1 Biodata of Informants

\subsection{Research Method}

The researchers opted for the qualitative research approach to explore, in-depth, the phenomenon of code-switching based on the long experience and profound expertise of the participated informants. This method enabled the researchers to gather rich and thick data via the conducted one-to-one interviews. Due to the current global aftermath of Coronavirus 
Covid-19, the interview questions were forwarded to the informants through private WhatsApp messages and E-mail correspondences. In particular, this is due to the postponing of the new school year 2020/2021 start until November 2020 by the time this research was conducted.

\subsection{Research Instrument}

Based on the research questions, the researchers designed an interview tool consisting of five major questions. The interview tool was checked for validity by two experts who are highly involved in English education research work and well familiar with the research topic area. The received feedback was put into thoughtful consideration to improve the interview tool in terms of the face and content as to achieve clarity and to address the focal research point. Having the responses via WhatsApp application and E-mail corresponding system enabled the researchers to go back to the purposeful sample of informants, easily and immediately, for further follow-up questions or clarifications, whenever necessary. In the main, the researchers know very well where the responses of the informants come from, especially knowing that the main researcher is part of the English Supervisory field within Muscat Educational Governorate for just more than two decades.

\subsection{Data Analysis}

Based on the qualitative nature of this research study, the researchers used the NVivo Software to establish a coherent coded thematic analysis (TA). This internationally recognized qualitative software enabled the researchers to store and manage the qualitative data in a smooth and systematic manner. For validation purpose, a sample of the generated themes was introduced to a couple of experts in the English Language education and supervision field for evaluation and critical feedback. The Inter-rater Reliability form followed the template suggested as in Sheikh (2017: 33-50). The received feedback proved that the generated themes are appropriately in alignment with both the research questions and the responses of the informants with an average of $95 \%$ agreement.

\section{Interview-based Qualitative Findings}

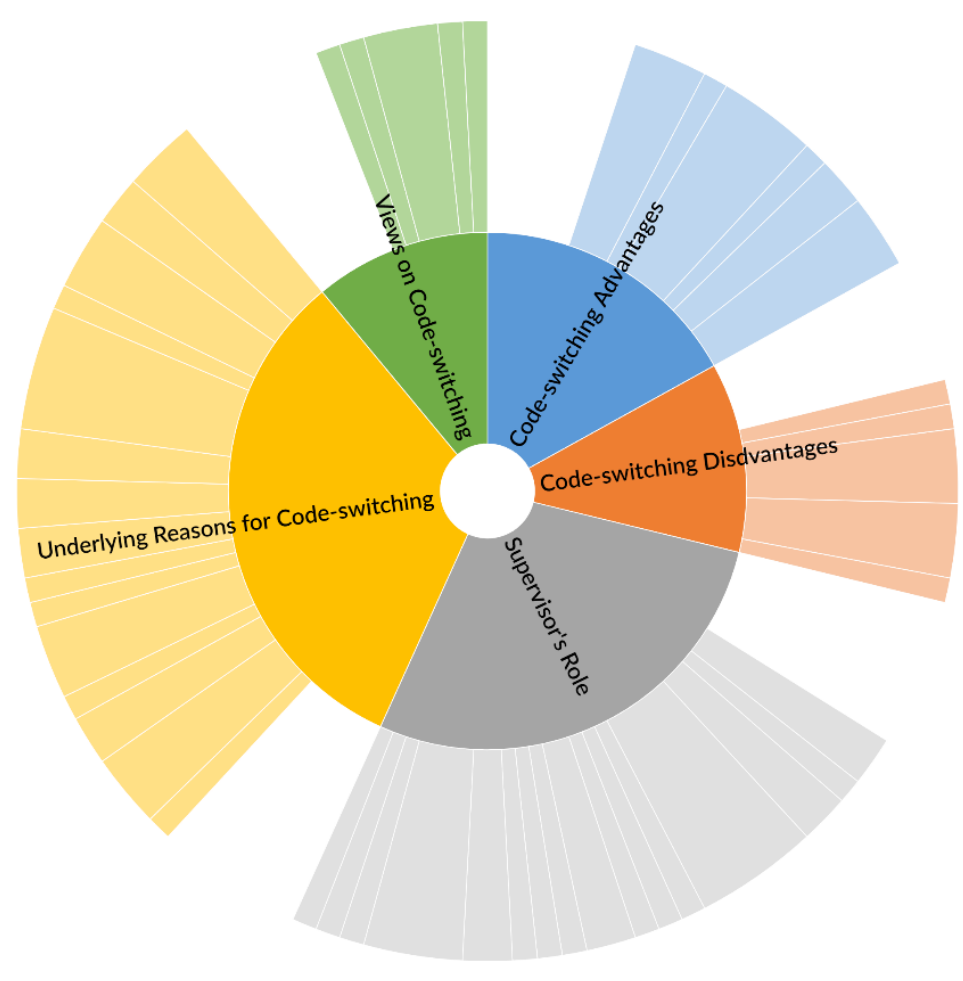

Figure 2 Sunburst Chart of the five Parent Themes

The thematic analysis (TA) generated five parent themes which correspond to the research questions, with a group of child themes propagated out of the five parent themes as illustrated in Figure2 as attached above. Obviously, the informants provided more rich and thick data in their response to the question tackling the underlying reasons towards the teachers' code-switching in addition to the question addressing the supervisors' role towards this phenomenon. Interestingly, the least generated child themes, among all the five parent themes, fall under the disadvantages of code-switching, as the following cluster chart illustrates: 


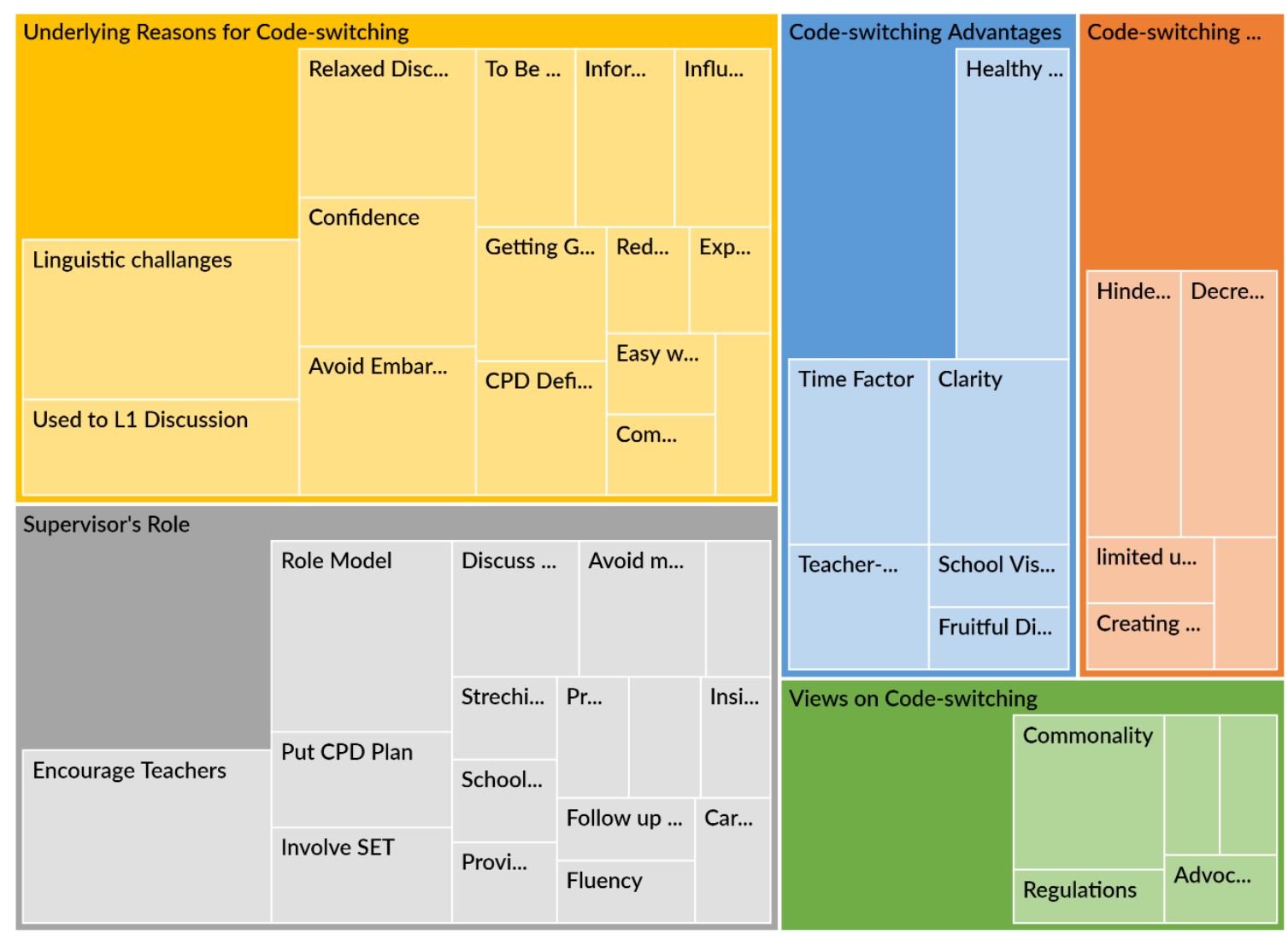

Figure 3 Thematic Analysis Cluster Chart

\subsection{The English Supervision's Perspectives on Code-switching}

Based on their long field experience in EFL education and supervision, the involved informants shared their views about the phenomenon of code-switching as a 'common practice especially among C1 teachers', Informant1 said. A linguistic strategy that, according to Informant3, is influenced by the native language of 'many teachers around the world whose English is not their first language would probably use this as a way to clarify things'. Likewise, Informant5 elaborated, 'Code-switching is a normal linguistic phenomenon practiced by bilinguals. Usually the native language is more dominant than the second language that is why the speaker switches to it very often. On the other hand, Informant6 highlighted that 'code-switching is a bit different from code-mixing; the first one is done in purpose while the second is articulated naturally due to several reasons'.

Though to Informant2 code-switching 'can be acceptable and beneficial for some teachers', still, it 'can be the last resort used during the post lesson discussion between RS and the teachers for some specific expressions but it is preferable not to be overused', Informant4 pointed out.

According to Informant5, 'in view of the teachers' use of code-mixing, it is of no exception and I don't see any problem in using code-switching during the PLD especially for isolated educational terminologies or a few expressions particularly when the two speakers share the two spoken languages for communication. Teachers are allowed to use Arabic in the classroom with their students, so why not in the PLD? Besides, there is no specific rule that regulates the spoken language outside the classroom. RSs use code-mixing, so why not the teachers? especially if it is well managed and used with wise judgement'.

As opposed to the above view, Informant6 bluntly expressed his objection: 'Code-switching and/or code-mixing during the PLD is an unwanted strategy done by a teacher in C1, C2 or C3. But, it might be a sign for SET and RS that the teacher is encountering some difficulties'.

From a middle point of view, Informant7 explained: 'Well, as our ultimate goal is to develop the English teachers' fluency, I think it is advisable to encourage teachers to use English. Teachers can only switch to $L 1$ when it is very necessary. For example, if they fail to express something in English or get equivalent terminologies or vocabulary to convey their messages'. 
However, and from a personal perspective, Informant 8 said: 'I personally do not prefer using code-mixing as I sometimes feel lost in the middle of the discussion especially at work or in teaching. However, I do not think it is a big issue in daily communication as long as the person is comfortable and is not rude to others'.

\subsection{The Underlying Reasons for C1 EFL Teachers' Code-switching}

According to Informant1, C1 EFL teachers' recourse to code-switching for a number of reasons for example 'due to the difficulties in finding out the proper words or expressions during the conversation. Others may switch to their L1 language during interaction to make conversation faster especially at informal PLD. Some new teachers also use it because they feel unconfident to speak fluently in English'.

On another level, Informant $\mathbf{2}$ added further: 'Some teachers use it when they want to explain more about a specific matter. Some teachers feel more comfortable when they use their native language. They might think that in this way they can make sure that the RS or SET understands them. In addition, may be they have a limited number of vocabulary which help them to use English language. Sometimes because of lack of confidence or some teachers have to express their message clearly enough in their language'.

Informant 3 added: 'Sometimes teacher feels $L 1$ use has like a friendly and informal feel to the discussion done especially if the teacher is newly appointed or still not very familiar with the RS or SET they are starting to deal with. They use it because they lack some sophisticated educational vocabulary. This could be the main reason but there could be other reasons like lack of confidence, breaking the formal feel of the conversation from very serious to less serious and so to a less stressful conversation'.

From a professional perspective, Informant 4 elaborated: 'If $C 1$ teachers frequently use code-switching during the post lesson discussion, they have a deficiency of personal and professional development. They need to be involved in a strategic training programme for one to two years by monitoring the impact of their training. Broadly speaking, the need for more coaching and mentoring programmes regarding pedagogy, TKT, CELTA, DELTA course to enrich their teaching knowledge, skills and experience. Some $\mathrm{C} 1$ teachers have lack of subject knowledge to express themselves clearly during the post lesson discussion due to low preparation in the academic programme prior to joining the real teaching context. As for professional development, C1 teachers need to improve personal professional development by involving themselves in training programmes such as webinars, online courses, reading journals or participating in online forums or CPD platforms'.

Informant 5 highlighted, 'Some teachers refer to code-mixing as a natural bilingual act in a spontaneous way. They feel more comfortable to use Arabic with English during the discussion especially known that English teachers who share and speak Arabic with each other outside the classroom. Some teachers use Arabic more if the RS or SET does not mind. As for C1 in particular, some teachers are influenced by the level of their students and get used to simple English language and the English mixed with Arabic. So, they transfer the same classroom language to PLD. Some other teachers are not competent in their English that is why they use Arabic more to express themselves in a more comfortable way to avoid any embarrassment. So, RSs understand this and they do not mind especially if the teacher's classroom language is good and the teacher is using successful pedagogical techniques. Other teachers are used to discuss the class in Arabic with the SET informally. So, they do the same with the RS and struggle in expressing their ideas in a professional way because they are not used to the professional protocol of PLD'.

In the same way, Informant 8 added: 'Sharing the same language normally leads to code-switching as many feel relaxed when using own language especially with humor. Majority also use it as a trend and imitate celebrities when they talk. That is very clear when watching an Arabic TV interview or programme, to observe how they use code-switching. Then by time it turns to be a habit. Some teachers in our $\mathrm{C} 1$ schools do not have the fluency and the confidence to express themselves in English. So, they prefer code-mixing'.

Informant 6 summarized the reasons to include, '1) avoiding ambiguity with other terms, 2) they may have a shortage of vocabulary, 3) being afraid of mis-pronouncing a word, 4) trying to be simple, 5) being used to switch to L1 with the SET and teachers in the school, 6) they are afraid of making grammatical errors or 7) they are nervous and they want to hide any one of the above points'.

To Informant 7, 'It is probably happening due to the lack of English proficiency. They might not be good enough to communicate in English, so they switch to Arabic to avoid making mistakes in English in front of the evaluators; RS or SET. Another reason, teachers might have learned particular techniques or strategies while observing Arabic teachers. So, the strategies themselves are taught in Arabic and therefore it is easier for English teachers to explain as they learnt them instead of shifting to English translation'. 


\subsection{The Potential Advantages of Code-switching}

Not only code-switching is used by teachers but Supervisors too. Informant 1 explained: 'code-switching helps RS to end the discussion in a short time especially with new teachers who feel reluctant in speaking in English and the RSs who has limited time to observe other teachers. So, time is of essence especially that the focus of RS is to achieve the goal of the school visit with all the targeted teachers during the school visit and to cover classroom observations as quickly as possible. RS cares for the accuracy more than fluency; thought content rather than the words'.

Informant 2 added: 'In terms of comprehension, it may help the teacher to use it effectively to prevent confusion. It may also help some teachers to feel encouraged and supported'.

On the same token, Informant 3 explained: 'Using Arabic can clarify things more easily. It can lead to not wasting too much time on matters discussed. It can reduce the stress of the discussion especially with newly appointed teachers. It helps to cross the very formal boundaries between the teacher and the supervisor of the senior teacher to make the conversation more of a formal free. It helps especially new teachers to have a more of a friendly relationship with the supervisor or the senior teacher'.

As for the bilateral teacher-supervisor relationship, Informant 4 said: 'Using Arabic in the PLD may close the gap between the teacher and RS when there is a misconception. It also provides clarification for some essential points about the taught lesson'.

In the same way, Inofrmant 5 added: 'Code-mixing can bring a few advantages in the short run. For example, conducting quick and stress-free fruitful discussion'.

From his side, Informant 6 explained: 'I don't know if we could call them advantages of using L1. However, teachers feel comfortable to answer in L1. They also feel confident of what they articulate as they believe their message is delivered correctly. It could be creative if the teacher is very clever when she just throws a word or two then complete the discussion in L2. It is then, fine'.

Informant 7 added: 'Code-switching could be useful when it is used for a genuine need. When teachers encounter difficulties in expressing certain things in English or do not have equivalent terminologies or vocabulary to convey their messages or when teachers want to elaborate or clarify something'.

Holding a similar perspective,Informant 8 further explained : 'Using code-switching provides stress-free environment particularly when conversing in a positive manner and accepted by others .It might help to express feelingpersuade others , and share humour which is difficult to be translated in a different language'.

\subsection{The Possible Disadvantages of Code-switching}

According to Informant1, 'Code-mixing deprives the teacher and the Supervisor from using the formal communication language which is English. It is not professionally appropriate to mix both. If the teacher gets used to code-witching, she will keep using it in her classroom language too as a habit turning her teaching language to English and Arabic. So, it is better to avoid code-mixing in conducting PLD'.

From her side, Informant 2 added: 'Teachers using code switching will mix between the grammar of the two languages and will not practice English enough and fluently'.

From English proficiency standpoint, Informant $\mathbf{3}$ said: 'Code-switching may lead the teacher to stay on the same language level and they would not have the aspect of challenging themselves or even the need to do so in contradict with the idea of professional development especially on the language aspect. Hence, they would stay on the same teaching level; only at elementary level not up to secondary level for years. This may trigger a main problem'.

Infromant 4 pointed out, from a professional development angel, 'Sticking to L1 use may hinder the teacher's professional development and it may reduce vocabulary knowledge and updated teaching practice'.

Similarly, Informant 5 clarified: 'This will influence both the RS and the teacher's English and educational knowledge in the long run especially if no effort is put to minimize the use of Arabic during the discussion. This will focalize the teacher's knowledge and will eventually affect the teacher's classroom language. In this sense, the teacher will not professionally develop and will be in the same spot and won't be suitable to promote to teach in higher grades'.

As well, Informant 7 explained further: 'If teachers overuse $L 1$ in the PLD, their English is going to become poor. Consequently, lots of techniques names and terminologies are going to be forgotten. This could be considered as disadvantages of using code- switching'. 
From another level of the teacher's evaluation, Informant 6 pointed out: 'Code-switching or code-mixing may affect the mark giving in the classroom observation form. Code-switching is not healthy for English teacher who might lose the level of good English gradually. It gives an awkward impression about the teacher's overall performance in the usual lessons when the SET or RS is not there'.

Informant8 pointed out further complications: 'Depending on code-switching may lead to language deficiency and might affect own fluency and accuracy. Teachers may get used to it in their classes. As a result, students do not bother themselves to learn the language and that will influence their study'.

\subsection{Supervision's Role Towards C1 EFL Teachers' Code-switching}

Informant 1 said: 'RS should point to the teacher to use English as the target language to attain more fluency. To save time, RS may ask the teacher to be more specific and right to the point. Also, giving more input during the workshop sessions about the post lesson discussion language and encouraging the teacher to read more to improve English language competence'.

By the same token, Informant $\mathbf{7}$ said: 'RS should encourage teachers to speak English as much as they could while discussing. They could switch to English whenever the teacher starts to speak Arabic or paraphrase what the teacher says in English or by simplifying their English and paraphrasing their question'.

From a motivational perspective, Informant 2 elaborated: 'It is very important that RSs know their teachers and show care for them. This may encourage them to make effort to communicated in the target language. It is important that RSs don't correct every and each mistake during the discussion'.

As well, Informant 3 added: 'RS's role is to encourage teachers to use English as the discussion language and to hold a meeting, at least at the beginning of the year, as to mention the importance of language use during discussions and in the teacher's professional development. Supervisor can be a model who teachers would look up to and so the supervisor would always say the English equivalent to the Arabic one. English teachers should be using English as a speaking language during their formal working hours; a rule should be imposed by MOE. Only during breaks teachers could use L1. Supervisor could suggest to teachers to go for field visits to other good schools to attend the discussions done well in English; $\mathrm{C} 1$ teachers observe C2 teachers. Supervisor could ask the SET to come up with events like having quizzes competition between teachers to promote the use of English. Supervisor would need to follow those teachers with language deficiency from the beginning of the school year and may be enroll them in a language course'.

Thinking practical, Informant 4 explained: 'In my point of view, it is much better if the supervisor keeps using English-English interaction during the PLD to provide the teachers with the appropriate metalanguage to be used in the post lesson conference which enables the teachers to acquire some chunks or expressions. They can use them in other sessions. The more the supervisor is using English-English in the PLD, the number of teacher's clarifications in $L 1$ will be reduced because they get familiar with the language and the repetitive expressions. Many different educators point out the supervision for learning; the teacher may acquire some educational concepts from the supervisor when the post lesson discourse is English-English based which might enable the teacher to enrich his pedagogical vocabulary knowledge to use them in other education contexts or discussions. Moreover, English based language PLD supports teacher's cognitive dependence and linguistic background knowledge on English terminologies as a direct English education medium.

As a vigilant Supervisor, Informant 5 added: 'RS should observe what is going on in the school and how SET is communicating with her teachers. All should be challenged to increase their language level and advance their communication and discussion skills to make sure a real professional development is taking place. It is also important not to suppress incompetent teacher and takes her hand where the teacher goes through a gradual development in terms of the PLD language and protocol. In this case, an action plan should be drawn to address the actual reasons behind excessive cod-switching'.

The supervisor as a coaching mentor to teachers, Informant 6 explained: 'The teacher should be informed gently about this issue that she should get rid of. It is a bad habit that is not preferable in PLD. Especially, if the teacher is an easy-going teacher. If she is a hard-headed, then she needs to be convinced gradually and nicely until she gets along. RS or SET could use different strategies while doing the PLD. Supervisor could repeat the teachers sentences or words into L2 while talking to the teacher as this will urge the teacher to use L2, pretending that you are not happy about using L1, in a funny way, and insisting on answers in English. RS or the SET should be exemplary for teachers and they all should speak using English in the school. Amending teacher's code-switching or mixing by encouraging them to use L2. This encouragement could vary depending on the teachers' characteristics'. 
On the same token, Informant $\mathbf{8}$ added: 'RS needs to convince teachers through discussion and research studies. Also, observe her in the class and give instant feedback regarding the drawbacks of code-mixing'.

\subsection{Thematic Concepts Map}

Based on the responses of the informants, the following mind-map illustrates the generated themes out of the five major themes corresponding to the research questions:

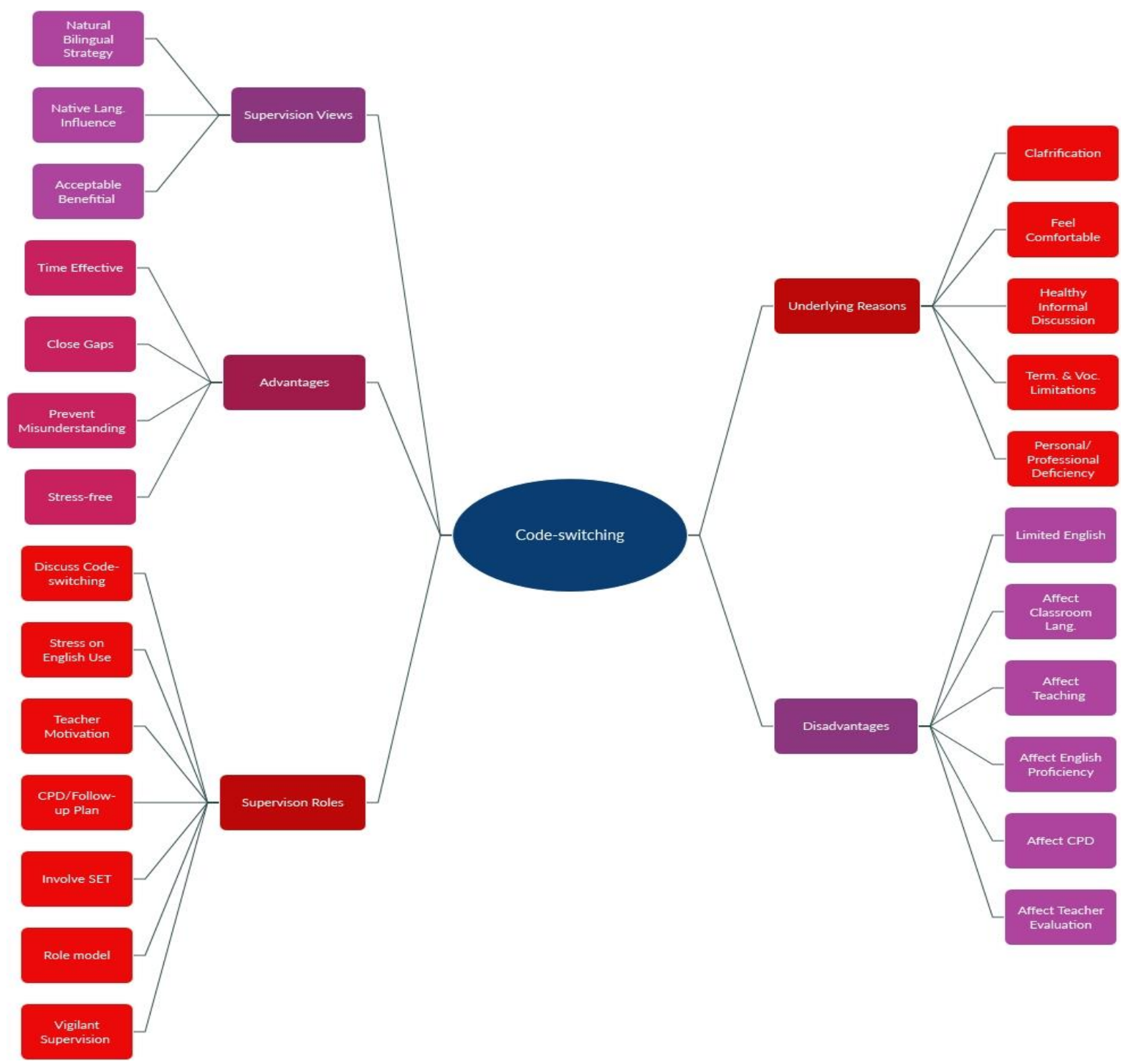

Figure 4 Themes Mind Map

\section{Discussion of Findings}

The informants' responses indicated that there is a common understanding and full awareness of the code-switching phenomenon as a natural bilingual activity as evident in the reviewed literature (e.g. Green \& Li, 2014; Green \& Wei, 2016; Ansar, 2017). The controversial nature of this issue also emerged as it is the case between the communicative approach and the use of native language in the foreign language learning world. This leaves the informants with three debatable perspectives towards code-switching use; 1) opponents, 2) advocates and 3) those who are in between calling for judicious discretion of code-switching. The below attached pie chart illustrates the number of informants categorized according to the three perspectives; 1 opponent, 4 advocates, 4 with wise discretion of code-switching. 


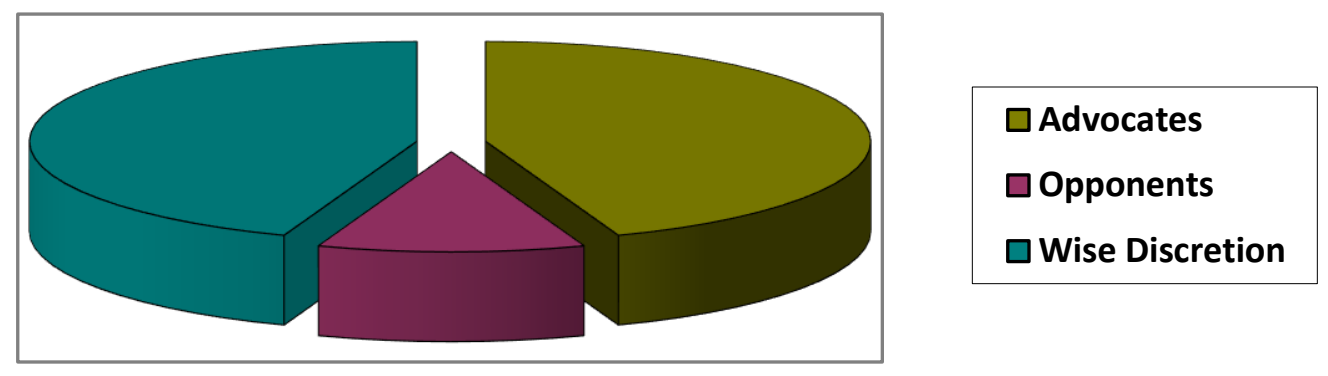

Figure 5 Perceptions on Code-switching

The reasons for code-switching use revealed by the informants also match with the ones discussed in the reviewed literature. In one way or another, all the reasons fall under the three functions stated by Mattson and Burenhult (1999); 1 ) topic switch, 2) affective functions and 3) repetitive functions. Interestingly, the informants, as Supervisors and Senior Supervisors, are fully alert of this phenomenon as well as the underlying motives of the teachers and how to be approached, yet from one-sided individual perception. Nevertheless, if all the pieces from each informant were put together, the code-switching phenomenon could be handled in a more professional and systematic manner as a unified English Supervision strategy, with the team effect in mind. The following points summarize the main reasons for codeswitching:

a) Natural bilingual act in a spontaneous way

b) No objection from RS or SET

c) Fast and brief conversation

d) L1 use has friendly and informal feel to the discussion

e) Sharing the same language normally leads to code-switching

f) Discussing the observed class in Arabic with the SET; fixed habit

g) Struggling in expressing ideas as they are not used to PLD professional protocol

h) Having difficulties in finding out the proper words or expressions

i) Bing influenced by the level of students

j) Getting used to simple English language and the English mixed with Arabic

k) Feeling more comfortable when they use their native language

I) Feeling relaxed when using own language especially with humor

m) Expressing message clearly enough; avoid any embarrassment

n) Feeling unconfident to speak fluently in English; particularly newly appointed teachers

o) Bing afraid of mis-pronouncing a word; avoid making mistakes in English in front of the evaluators

p) Lack of English proficiency

q) Lack of subject knowledge; educational terminology to express themselves

r) Deficiency of personal and professional development

As a double edged sword, code-switching holds some advantages and disadvantages to both the C1 EFL teacher and her RS or SET (as a resident supervisor). However, and from a technical outlook, the few disadvantages discussed by the informants are more significant in the long term and overweigh the potential short term advantages, especially when putting the CPD in mind. The following graphic illustration displays the two sides of code-switching: 

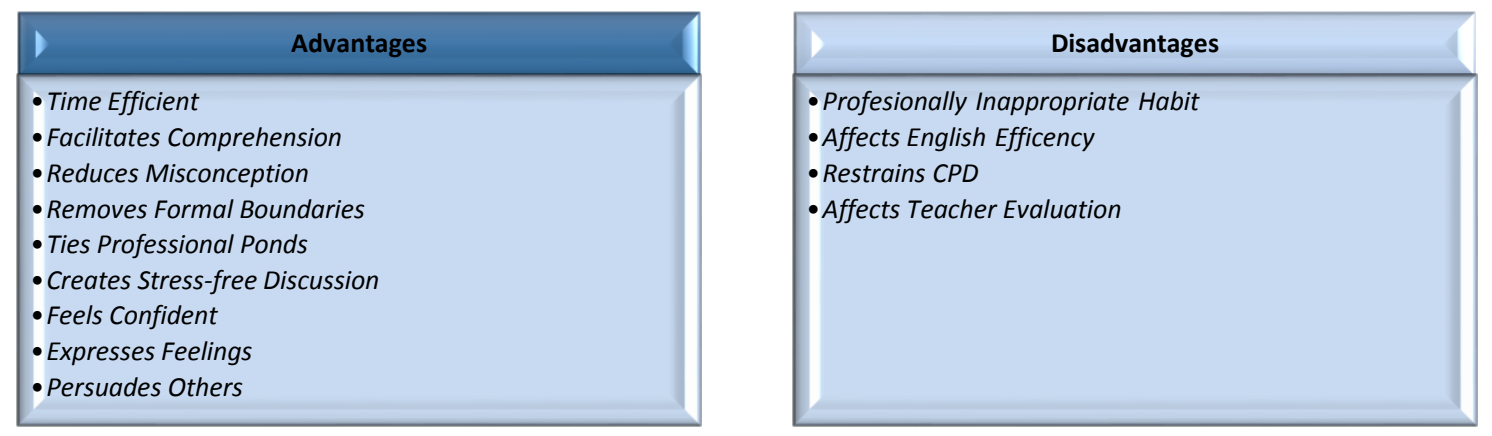

Figure 6 Code-switching Pros \& Cons

Having this said, it is evident that the English Supervision plays a major role in addressing the code-switching phenomenon leading the way to the teacher for better practices within the school framework; both in/outside the classroom. The following section discusses in depth the expected role of EFL Supervision as seen from the informants themselves as EFL RS(s) and Senior RS(s).

\subsection{Supervision-related Recommendations}

As articulated by the informants, the supervisory roles of RS(s) and/or Senior RS(s) towards an effective management of $\mathrm{C1}$ EFL teacher(s)' code-switching is summarized in the following points:

a) Stressing on English language proficiency as the optimal goal; English as the formal medium of communication.

b) Acting as a role model in speaking English only in front of your teacher(s).

c) Addressing the code-switching phenomenon directly/indirectly.

d) Introducing alternatives for code-switching in PLD as part of the code-switching management.

e) Creating a healthy work experience and stress-free discussion environment.

f) Motivating and encouraging teachers on personal and professional levels.

g) Making vigilant observations and act accordingly.

h) Studying the characters of your teachers in order to know how to influence them.

i) Sharing your observations with the SET and involve her, as a resident Supervisor.

j) Sharing the agreed upon observations with the teacher herself and involve her in her future CPD plan.

k) Designing and/or tailoring a practical CPD plan based on individual teacher analysis. Avoid free size and/or ready made plans.

I) Following-up CPD and gather regular feedback and progress accordingly using formal/informal school visit reporting forms.

m) Investigating and addressing the code-switching phenomenon; knowledge is mightier than sword.

\section{Conclusion}

Code-witching, as an alteration from one language to another in the same conversation, is a natural strategy among bilinguals. From a local pedagogical outlook, this research explored the Omani C1 EFL teachers' code-switching as conceived by the English Supervision to achieve better awareness on the phenomenon for more effective and professional dialogue. The achieved findings are in match with the existing knowledge manifested in the reviewed literature which prove that code-switching in the world of languages is pretty the same despite the nuances of the linguistic and/or sociolinguistic differences. The gender variable showed no significant findings as the male and female informants produced similar professional responses to the research topic without any recognized gender effect. Furthermore, the underlying reasons for code-switching are, more or less, similar to the known reasons for the use of translation; especially knowing that code-switching and translation are tangled linguistic areas. That explains the controversy of code-switching as perceived by the informants who are to some extent take it as a reflection to translation and/or native language use. As the essence of the research study, the suggested supervisory recommendations by the informants, as the experts of the English 
Supervision at MoE, pave the way for a better understanding of the teachers' code-switching in the PLD in terms of handling it in the most effective and professional possible way. Most importantly, the findings open new windows of research opportunities branching from the area of mother tongue use in the foreign language dialogue; in/outside the classroom pedagogical or sociological contexts.

\section{About Authors}

AlGhaliya AlKindi is working for Ministry of Education in Sultanate of Oman as the Head of Human Sciences Section at Muscat Educational Governorate with 21 years of experience in EFL education. She holds two educational qualifications from Sultan Qaboos University; B.Ed. in English Language (2000) and MA in Translation Studies (2014). Also, she holds a Diploma in Professional Practices for Educationalists; Expert Supervisors Programme. Currently, she is doing her PhD in Education at International Islamic University Malaysia. AlGhaliya's research interests include EFL Education, EFL Supervision, Translation Studies and Human Resources Management. ummalmutaz.888@moe.om

Ismail Sheikh Ahmad is Professor at the Kulliyyah of Education of the International Islamic University, Malaysia (IIUM). He earned his Bachelor of Arts from Fresno State University, California (1985), Master of Science from University of Southern California (1986), Diploma in TESL, RELC, Singapore (1989) and PhD from the University of Nottingham, England (1997) and has published articles on second language reading and literacy, presented papers and invited keynote speaker in local and international language education conferences. His specialized areas include qualitative research methodology, English teaching methodology, reading literacy, critical and creative thinking skills and curriculum design. drismail@iium.edu.my

\section{References}

[1] Al-Alawi, T. (2008). Teachers' Beliefs and Practices about the Use of L1. Investigating English Language Teaching and Learning in Oman. MOE, Oman.

[2] Al-Hadhrami, A. (2008). The Role of the L1 in Grade 5 EFL classrooms. In S. Borg (Ed.). Investigating English language teaching and learning in Oman. Muscat. MOE, Oman.

[3] AlKindi, A., Sheikh Ahmad, I., Al-Sharafi, A., Idrus, F. (2020). The Impact of Translation Use on EFL and FFL Learning from the Perspective of Grade11 Omani Students: A Qualitative Case Study. International Journal of Research in Humanities, Arts and Literature (IMPACT: IJRHAL), V8 (9), 77-94.

[4] Ali, H. (2020). Omani Students' Coping Strategies in an English Medium Engineering Programme. Arab World English Journal (AWEJ), 11 .

[5] Al-Jadidi, H. (2009). Teaching English as a Foreign Language in Oman: An Exploration of English Language Teaching in Tertiary Education. Unpublished PhD.

[6] Al-Ma'ani, M., \& Al-Kindi, A. G. (2017). Translation and EFL in Oman. Journal of Arts \& Social Sciences (JASS), 8 (3), 5-14.

[7] Al-Qaysi, N. J. M. (2016). Examining Students' and Educators' Attitudes Towards the use of Code-Switching within Higher Educational Environments in Oman (Doctoral dissertation, The British University in Dubai (BUiD)).

[8] Al-Shidhani, A. (2009). Teachers' Beliefs about Using Arabic in the English Classroom. In S. Borg (Ed.). Classroom Research in English Language Teaching in Oman. Muscat: Ministry of Education, Oman, 184-191.

[9] Ansar, F. (2017). Code Switching and Code Mixing in Teaching-Learning Process. English Education: Jurnal Tadris Bahasa Inggris, 10 (1), 29-45.

[10] Cahyani, H., de Courcy, M., \& Barnett, J. (2018). Teachers' code-switching in bilingual classrooms: exploring pedagogical and sociocultural functions. International Journal of Bilingual Education and Bilingualism, 21(4), 465-479.

[11] Cantone, K. F. 2007. Code-switching in Bilingual Children. Dordrecht: Springer

[12] Green, D. W., \& Li, W. (2014). A control process model of code-switching. Language, Cognition and Neuroscience, $29,499-511$.

[13] Green, D. W., \& Wei, L. (2016). Code-switching and language control. Bilingualism: Language and Cognition, 19(5), 883-884.

[14] Losey, K. M. 2009. Written Code-Switching in the Classroom: Can Research Resolve the Tensions? International Journal of Bilingual Education and Bilingualism, 12 (2): 213-230

[15] Mattsson, A \& Burenhult-Mattsson, N. (1999). Code-switching in second language teaching of French. Working Papers, 47: 59-72.

[16] Numan, D. and Carter, D. (2001). Teaching English to Speakers of Other Language. Cambridge: Cambridge University Press. The Internet TESL Journal. Available http://iteslj.org/Articles/SertCodeSwitching.html

[17] Omar, A., \& llyas, M. (2018). The Sociolinguistic Significance of the Attitudes towards Code-Switching in Saudi Arabia Academia. International Journal of English Linguistics, 8(3), 79-91.

[18] Sert, O. (2005). The Functions of Code-Switching in ELT Classrooms. Online Submission, The Internet TESL Journal, 11(8). Available https://files.eric.ed.gov/fulltext/ED496119.pdf

[19] Sheikh, I., (2017). Doing Qualitative Research for Beginners: From Theory to Practice. Partridge. Singapore.

[20] Tekin, A. K., \& Al-Salmi, L. (2019). How and Why Bilingualism is Being Promoted by Omani Parents and How Bilingualism is Impacting their Children's Everyday Lives. International Journal of Learning, Teaching and Educational Research, 18(12), $136-149$.

[21] Wardhaugh, R., \& Fuller, J. M. (2014). An introduction to sociolinguistics. John Wiley \& Sons. 
[22] Wei, L. (2005). “How can you tell?": Towards a common sense explanation of conversational code-switching. Journal of Pragmatics, 37(3), 375-389.

\section{Appendix A: Interview Questions}

1. What do you think of Code-switching or code mixing (English-Arabic) used by C1 EFL teachers during the PLD?

2. Why do $\mathrm{C} 1$ teachers refer to code-switching during the PLD with you or with the senior teacher?

3. What are the potential advantages of code-switching for the long/short run?

4. What are the possible disadvantages of code-switching for the long/short run?

5. What is the role of the supervisor towards handling code-switching (solutions/ suggestions/ recommendations)? 